\title{
Questions on Immunization and Vaccination and Short Answers
}

\author{
Bağışıklama ve Aşı ile Illgili Sorular ve Kısa Cevaplar
}

\author{
Ateş Kara'(iD) \\ ${ }^{1}$ Division of Pediatric Infectious Diseases, Department of Pediatrics, Hacettepe University School of Medicine, Ankara, Turkey
}

Cite this article as: Kara A. Questions on immunization and vaccination and short answers. J Pediatr Inf 2020;14(4):e233-e234.

Question 1: How should the approach be in situations where the child's vaccination status is unknown or unclear?

A child's vaccination status can be found out by reviewing the history, vaccination card and medical records of the child. Among these, history is known to be insufficiently reliable. Since it is administered annually, only the oral history of flu vaccination can be accepted.

In order to determine the vaccination status of the individuals, information should be received from the vaccination card or vaccination records of the healthcare center. In individuals whose vaccination status cannot be reached on paper or digitally, routine serologic test is not recommended due to reasons such as difficulty in implementation and the failure of the non-standard methods in showing protection. Therefore, all children and adults without proper vaccination card or vaccination record should be started to be vaccinated by accepting them as unvaccinated.

In the event of not having any records of vaccination of the individual, general information on the possibility of the vaccinations being administered more than the recommended dosage or more frequently than recommended:

- It is known that the frequency of side effects decreases in the repeat doses of live vaccines.

- In children aged under 6 years with no records of vaccination status, BCG vaccination does not have to be repeated if there is a BCG scar.
All individuals, whose vaccination status is not known, should be vaccinated anew with the age-appropriate immunization calendar of the unvaccinated person. However, if the decision not to continue with the repeat doses of the vaccine has been made by the ASIE Commission (ASIE: adverse effects after vaccination; see ASIE Monitoring System Notice) due to previous vaccine-related systemic or local serious side effects, then these individuals should be evaluated as incomplete vaccination.

Question 2: What are the protective durations of the vaccinations?

The potentially shortest protective durations of some vaccines are given in Table 1.

Question 3: Can vaccinations be administered from an anatomic site with a tattoo on?

Yes, they can. Vaccinations administered intramuscularly or subcutaneously can be administered through the site with the tattoo.

Question 4: Are there any vaccines to beware of if more than one vaccine will be administered simultaneously?

There is no problem in administering the vaccines on the same day. More than one vaccine can be administered on the same day. Particularly, in children who are late at the vaccination calendar may have to be vaccinated with multiple vaccines on the same day. Hepatitis B, BCG, DaBT-IPA-Hib, CPV, OPV, $M M R$, varicella, and hepatitis $A$ vaccines can be administered

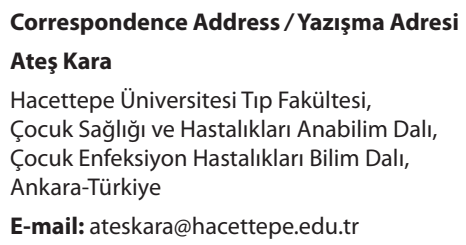

Correspondence Address / Yazışma Adresi

Ateş Kara

Hacettepe Üniversitesi Tıp Fakültesi,

Çocuk Sağlığı ve Hastalıkları Anabilim Dalı,

Çocuk Enfeksiyon Hastalıkları Bilim Dalı,

Ankara-Türkiye

E-mail: ateskara@hacettepe.edu.tr

Received: 16.10 .2020

Accepted: 07.11 .2020
Available Online Date: 18.12 .2020
(C) Copyright 2020 by Pediatric Infectious Diseases and Immunization Society. Available online at www.cocukenfeksiyon.org 
on the same day. Administering many vaccinations on the same day does not suppress immunity.

- There are two exceptions where two vaccinations cannot be done on the same day though there is indication for both vaccines:

- Conjugate pneumococcus and polysaccharide pneumococcus are not administered on the same day in risk groups who need to be vaccinated with both (for instance, chronic pulmonary, chronic heart, chronic kidney diseases, immunosuppressed individuals, those with hyposplenism/asplenism, those with diabetes mellitus, and etc.). Polysaccharide pneumococcus vaccines are not used before the age of 2 years. Polysaccharide pneumococcus vaccine can be administered at least 8 weeks after the completion of age-appropriate conjugate pneumococcus doses in children between the age of 2-18 years. In adults ( $\geq 19$ years), first the conjugate pneumococcus vaccine is administered and then the polysaccharide vaccine is administered at least 8 weeks or 1 year later (according to the presence of risk).

- Both pneumococcus and meningococcus vaccines are indicated in those with congenital or acquired asplenia/hyposplenia. However, it is known that simultaneous administration of CPV-13 and 4-valent conjugate meningococcus vaccine of the brand Menactra (Men ACWY-D) causes a decrease in response to the 3 serotypes of pneumococcus. Therefore, if meningococcus vac- cine of the brand Menactra is to be administered in those with congenital or acquired asplenia/hyposplenia, it should be given at least 4 weeks after the completion of the CPV-13 series. There is no need for such duration in conjugate meningococcus vaccines of the Nimenrix or Menveo brand vaccinations in this risk group. They can be administered simultaneously with CPV- 13 vaccine or without any time interval.

- Paracetamol (first dose, half an hour before the vaccine administration, two other doses once in every 6 hours, hence in total, 3 doses) is recommended when meningococcus serogroup $B$, a non-routine vaccine, is administered simultaneously with any of the vaccines due to fact that it causes high fever. Conjugate meningococcus vaccines (Menveo, Nimenrix or Menactra) and meningococcus serogroup $B$ vaccine (Bexsero) can be administered simultaneously or without any time interval.

- Oral polio and rota vaccines can be administered simultaneously with childhood vaccines (including BCG) or without any time interval. If vomiting occurs in the 10 minutes of oral polio administration, then the vaccine is repeated. If vomiting occurs following the administration of rotavirus vaccine, then the vaccine is not repeated. When oral polio and oral rotavirus vaccines are administered simultaneously, oral polio should be preferred to be given first. Oral rotavirus vaccine can be given 5 minutes later.

Table 1

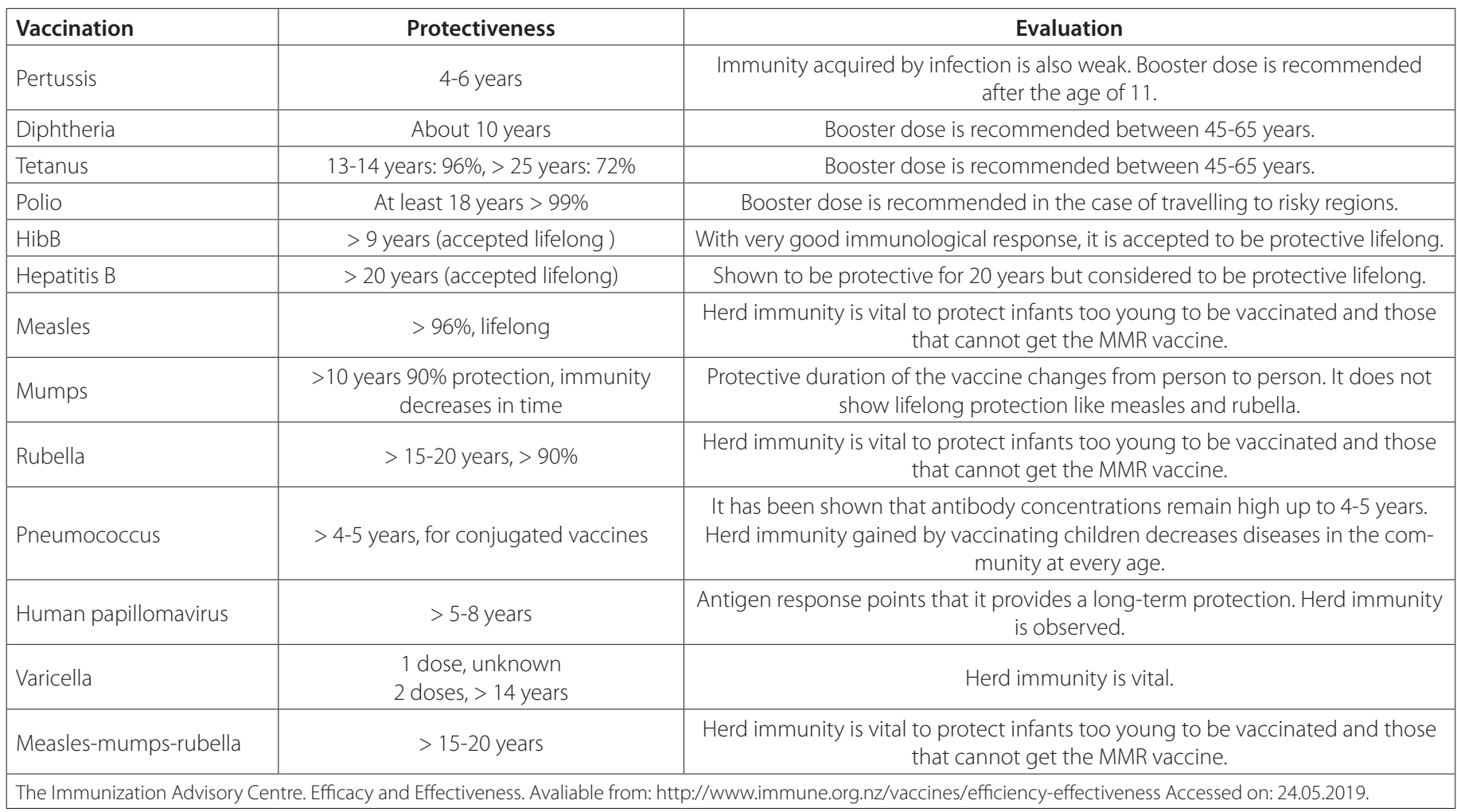

